\title{
1 A Brief Review of Cephalopod Behavioral Responses to Sound
}

2

3 Julia E. Samson ${ }^{1,2}$, T. Aran Mooney ${ }^{1,3}$, Sander W. S. Gussekloo ${ }^{2}$, Roger T. Hanlon ${ }^{3}$

4

$5 \quad{ }^{1}$ Biology Department, Woods Hole Oceanographic Institution, Woods Hole, MA

6 02543, USA

$7 \quad{ }^{2}$ Experimental Zoology Group, Wageningen University, 6708WD Wageningen, The

8 Netherlands

$9{ }^{3}$ Program in Sensory Physiology and Behavior, Marine Biological Laboratory, Woods

10 Hole, MA 02543, USA

11

12 Emails: jsamson@whoi.edu (JES), amooney@whoi.edu (TAM),

13 sander.gussekloo@wur.nl (SWSG),rhanlon@mbl.edu (RTH)

14

15 Corresponding author: T. Aran Mooney, 266 Woods Hole road, MRF MS\# 50,

16 Woods Hole, MA 02543, USA; amooney@whoi.edu

17

18 Keywords: Sepia officinalis, cuttlefish, sensory ecology, hearing, squid 
3 Sound is a widely available cue in aquatic environments and is used by many marine

4 animals for vital behaviors. Most research has focused on marine vertebrates.

5 Relatively little is known about sound detection in marine invertebrates despite their

6 abundance and importance in marine environments. Cephalopods are a key taxon in

7 many ecosystems but their behavioral interactions relative to acoustic stimuli have

8 seldom been studied. Here we review current knowledge regarding (i) frequency

9 ranges and sound levels that generate behavioral responses, (ii) the types of

10 behavioral responses and their biological relevance.

\section{Introduction}

13 24 2005).

Sounds are abundant in the ocean. They are produced by a range of organisms (e.g., fish, crustaceans, mammals, etc.) and by abiotic conditions (e.g., wind, waves, rain, earthquakes, etc.). Underwater sounds travel relatively fast $\left(\sim 1500 \mathrm{~m} . \mathrm{s}^{-1}\right)$, can be detected over long distances (Urick 1983), and are often available when sensory cues such as light or chemical stimuli may be limited (Popper \& Hastings, 2009). It is well established that many marine vertebrates detect and use sound for vital activities such as navigation, foraging, predator detection and reproduction (Fay \& Popper, 1999; Au et al., 2000). The ability of marine invertebrates to detect and potentially use sound is far less understood, which is somewhat surprising given their relative abundance and central role in many aquatic ecosystems (Budelmann, 1992a, b; Boyle \& Rodhouse, 
1 noted that octopuses reacted to low-frequency acoustic vibrations and water

2 movements. Later publications included the description of behavioral (Dijkgraaf,

3 1963; Komak et al., 2005), physiological (Kaifu et al., 2007), conditioned (Packard et

4 al., 1990), and neurological responses (Hu et al., 2009; Mooney et al., 2010) to sound

$5 \quad$ stimuli of different frequencies and intensities.

6 The organs generally thought to enable sound detection in cephalopods are the

7 statocysts (Hanlon \& Messenger, 1996; Kaifu et al., 2008). These are paired organs

8 located in the cartilage below the brain. They consist of a fluid-filled cavity

9 containing a macula-statolith system for the detection linear acceleration (e.g.,

10 gravity) and a crista-cupula system for the detection of angular acceleration (e.g.,

11 movement) (Budelmann, 1975). Polarized hair cells are found in both the maculae and

12 the cristae systems (Budelmann, 1979). The component of a sound field likely

13 perceived by cephalopods is particle acceleration, not sound pressure (Packard et al.,

14 1990; Mooney et al., 2010). In addition to the statocysts, Sepia officinalis (European

15 common cuttlefish) also has lines of epidermal hair cells, running over the head and

16 arms, that detect local water displacement (Budelmann et al., 1991; Hanlon \&

17 Messenger, 1996). Their contribution to sound detection is poorly understood.

18 In the past decades, the development and greater use of the ocean have led to a

19 concurrent increase in anthropogenic noise (National Research Council, 2005). This

20 noise may stem from many sources including shipping and vessel traffic, sonar

21 systems, seismic air guns, and oil drilling. Our increased awareness of the influences

22 of anthropogenic noise on the marine environment has led to several scientific studies

23 addressing its potential impacts on diverse marine life (e.g. Mooney et al., 2009;

24 André et al., 2011; Fewtrell \& McCauley, 2012). (André et al. 2011)

25 Cephalopods play an important role in ecosystems and are a key component of 
1 food webs, providing a vital link from smaller invertebrates and fish to marine

2 megafauna, birds, and humans (Boyle \& Rodhouse, 2005). It is therefore important to

3 investigate the potential impact of increased anthropogenic noise on cephalopods.

4 Changes in the behavior and distribution of cephalopod populations could have

5 substantial impacts on the survival and distribution of top predators such as marine

6 mammal, sharks, and sea birds; such changes would also impact commercial fisheries

7 (Boyle \& Rodhouse, 2005). In this paper, we review research regarding cephalopod

8 behavioral responses to sound, placing these studies in the context of potential noise

9 impacts. In particular, we address the frequency and sound level ranges that generate

10 behavioral responses in cephalopods, the types of behavioral responses elicited and

11 their biological relevance,

\section{Behavioral responses to various acoustic stimuli}

14

Cephalopods have a broad behavioral repertoire, including body movements (arms, mantle), body pattern changes, locomotor responses (jetting, fin movements) and inking (Hanlon \& Messenger, 1996). Multiple ethograms have been published (e.g. Hanlon \& Messenger, 1988; Hanlon et al., 1999 and references therein) and these provide the framework for future experiments in which behavioral responses to acoustic stimuli can be observed, recognized, and categorized in a quantitative manner.

Figure 1 summarizes cephalopod responses to sound. Dijkgraaf (1963) reported jetting, darkening of the skin, and narrowing of the pupils in S. officinalis in response to taps on the tank walls. Body patterning changes were observed when using $180 \mathrm{~Hz}$ tones. Juvenile cuttlefish exhibited changes in body patterning, 
1 displacements, and burrowing when exposed to local sinusoidal water motion from 20

$2-600 \mathrm{~Hz}$ (Komak et al., 2005). Certain frequencies generated substantially higher

3 levels of activity in juvenile animals. Unfortunately, the stimuli intensities (measured

4 as sound pressure level or particle motion) were not reported. Recently, using acoustic

5 stimuli ranging from $80-1000 \mathrm{~Hz}$ and a range of sound levels (measured in both

6 sound pressure and particle acceleration), Samson et al. (this conference, in prep)

7 categorized the behavioral responses of $S$. officinalis to different tones. The responses

8 included fin movements, body pattern changes, startle, jetting, and inking. Reactions

9 considered to be escape and/or startle behavior (blanching, jetting, inking) mostly

10 occurred at low frequencies and high sound levels. The average sound level needed to

11 elicit a certain response varied for each sound frequency.

12 Similar escape responses have been observed in squid Sepiotheutis australis

13 exposed to seismic air gun noises. The animals showed inking and jetting behaviors,

14 increased swimming speed, and swam upward, possibly to benefit from the sound

15 shadow near the water surface (McCauley et al., 2000; Fewtrell \& McCauley, 2012).

16 In Octopus ocellatus, Kaifu et al. (2008) reported changes in respiratory rates during

17 exposure to sounds $50-283 \mathrm{~Hz}$. Although octopuses are also capable of body pattern

18 changes, jetting, and inking, those behaviors were not mentioned in the literature as

19 responses to sound stimuli.

21 3. Potential for habituation to acoustic stimuli

Studies on the potential for habituation of cephalopods to any kind of stimulus

24 are scarce; most research on the learning capabilities of these animals has focused on

25 memory and spatial learning (e.g. Karson et al., 2003; Agin et al., 2006). Visual 
1 habituation to a predator model has been observed in the squid Lolliguncula brevis

2 (Long et al., 1989); the squids showed a decrease in body pattern changes and jetting

3 with repeated presentation of the fish models. Visual and tactile habituation were also

4 demonstrated in Octopus vulgaris; animals showed long-term habituation to visual

5 stimulation using a prey model, and a decrease in object handling over time (Kuba et

6 al. 2006).

7 Cephalopod habituation to acoustic stimuli has yet to be addressed in detail.

8 Only a few notes on the subject, collected en passant during previous studies on

9 sound detection in cephalopods, have been found in the scientific literature. Dijkgraaf

10 (1963) mentioned a very quick habituation to a $180 \mathrm{~Hz}$ tone in S. officinalis; after only

11 one exposure, the animals would not react to the stimulus anymore. Using juvenile $S$.

12 officinalis, Komak et al. (2005) obtained opposite results: no habituation was

13 observed to repeated stimuli of different frequencies ranging from $40-600 \mathrm{~Hz}$.

14 Following behavioral tests to different sound frequencies and levels, Samson

15 et al. (this conference, in prep) exposed S. officinalis to repeated sound exposure at

$16200 \mathrm{~Hz}$ and at different sound levels. A potential for habituation was observed;

17 response intensity decreased but response extinction was not reached within the time

18 of the experiments.

\section{Future research directions}

21

Studying behavioral responses in corroboration with physiological,

23 conditioned, or neural responses is a productive way forward to determine the

24 function of sound in cephalopod life history. Physiological responses, for example,

25 can provide information on detection ranges and thresholds (Hu et al., 2009; Mooney 
1 et al., 2010), but not on the use of sound by organisms and the role it plays in vital

2 behaviors such as feeding, defense or reproduction. Behavioral responses may also

3 reveal cephalopod functional use of sound stimuli. Moreover, knowing how animals

4 respond to sound is important from an ecological point of view (Hanlon \& Shashar,

5 2003) and should enable us to predict disruptive effects of anthropogenic sounds on

6 population behaviors (e.g., migration, spawning) and ecosystems, as there is a

7 substantial overlap among the hearing ranges of many key organisms and the ranges

8 of anthropogenic noise in the ocean (Figure 2). It is unclear which type of acoustic

9 information influences cephalopod ecology, given the low frequencies they react to,

10 and the absence of behavioral responses to ultrasonic clicks typical of odontocetes, a

11 prominent group of cephalopod predators (Wilson et al., 2007).

12 Microscopic studies have shown that the hair cells in the statocysts and

13 epidermal lines of S. officinalis and other cephalopods are polarized (Budelmann,

14 1979; Budelmann et al., 1991). This characteristic of the hair cells could be the

15 anatomical basis for directional hearing and sound location in cephalopods. The

16 ability to sense the direction of acoustic stimuli and the location of acoustic sources

17 has likely functions in defense but could also play roles in other behaviors including

18 navigation. Investigating these potentials in cephalopods might shed light on

19 important aspects of their sensory ecology.

21 References

23 Agin V, Poirier R, Chichery R et al. (2006) Developmental study of multiple memory

24 stages in the cuttlefish, Sepia officinalis. Neurobiol Learning Memory 86: 264-269.

25 doi: 10.1016/j.nlm.2006.04.001 
1 Au WWL, Popper AN, Fay RR (eds) (2000) Hearing by whales and dolphins.

2 Springer, New York

3 Baglioni S (1910) Zur Kenntnis der Leistungen einiger Sinnesorgane (Gesichtssinn,

4 Tastsinn und Geruchssinn) und des Zentralnervensystems der Zephalopoden und

$5 \quad$ Fische. Zeit Biol 53: $255-286$

6 Boyle P, Rodhouse P (2005) Cephalopods: ecology and fisheries. Blackwell Science

7 Ltd, Oxford

8 Budelmann BU (1975) Gravity receptor function in cephalopods with particular

9 reference to Sepia officinalis. Fortschr Zool 23: 84-98

10 Budelmann BU (1979) Hair cell polarization in the gravity receptor systems of the

11 statocysts of the cephalopods Sepia officinalis and Loligo vulgaris. Brain Res 160:

12 261-270. doi: 10.1016/0006-8993(79)90423-2

13 Budelmann BU, Riese U, Bleckmann H (1991) Structure, function, biological

14 significance of the cuttlefish "lateral lines". In: The Cuttlefish: $1^{\text {st }}$ International

15 Symposium on the Cuttlefish Sepia, Institut de biochimie et de biologie appliquée,

16 Université de Caen, Caen, 1-3 June 1989

17 Budelmann, BU (1992a) Hearing in Crustacea. In: Webster DB, Fay RR, Popper AN

18 (eds) The evolutionary biology of hearing. Springer, New York

19 Budelmann, BU (1992b) Hearing in non-arthropod invertebrates. In: Webster DB,

20 Fay RR, Popper AN (eds) The evolutionary biology of hearing. Springer, New York

21 Dijkgraaf S (1963) Versuche über Schallwahrnehmung bei Tintenfischen.

22 Naturwissenschaften, 50:50

23 Fay RR, Popper AN (eds) (1999) Comparative hearing: fish and amphibians.

24 Springer, New York

25 Fewtrell JL, McCauley RD (2012) Impact of air gun noise on the behavior of marine 
1 fish and squid, Marine Pollution Bulletin, volume 64, issue 5, 984-993. Doi:

$2 \quad$ 10.1016/j.marpolbul.2012.02.009

3 Hanlon RT, Messenger JB (1988) Adaptive coloration in young cuttlefish (Sepia

4 officinalis L.): the morphology and development of body patterning and their relation

5 to behavior. Phil Trans Roy Soc London Ser B Biol Sci 320: 437-487

6 Hanlon RT, Messenger JB (1996) Cephalopod Behaviour. Cambridge University

7 Press, Cambridge

8 Hanlon RT, Maxwell MR, Shashar N et al. (1999) An ethogram of body patterning

9 behavior in the biomedically and commercially valuable squid Loligo pealei off Cape

10 Cod, Massachusetts. Biol Bull 197: 49-62

11 Hanlon RT, Shashar N (2003) Aspects of the sensory ecology of cephalopods. In:

12 Collin SP, Marshall NJ (eds) Sensory processing in the aquatic environment.

13 Springer-Verlag, Heidelberg, Germany

$14 \mathrm{Hu}$ MY, Yan HY, Chung, W-S, et al. (2009) Acoustically evoked potentials in two 15 cephalopods inferred using the auditory brainstem response (ABR) approach. Comp

16 Biochem Physiol A 153: 278-283. doi: 10.1016/j.cbpa.2009.02.040

17 Kaifu K, Segawa S, Tsuchiya K (2007) Behavioral responses to underwater sound in

18 the small benthic octopus Octopus ocellatus. J Mar Acoust Soc Jpn 34: 266-273. doi:

$19 \quad 10.3135 /$ jmasj.34.266

20 Kaifu K, Akamatsu T, Segawa S (2008) Underwater sound detection by cephalopod

21 statocyst. Fish Sci 74: 781-786. doi: 10.1111/j.1444-2906.2008.01589.x

22 Karson MA, Boal JG, Hanlon RT (2003) Experimental evidence for spatial learning

23 in cuttlefish (Sepia officinalis). J Comp Psychol 117: 149-155. doi: 10.1037/0735-

$24 \quad 7036.117 .2 .149$

25 Komak S, Boal JG, Dickel L, et al. (2005) Behavioural responses of juvenile 
1 cuttlefish (Sepia officinalis) to local water movements. Mar Fresh Beh Physiol 38:

2 117-125. doi: 10.1080/10236240500139206

3 Kuba MJ, Byrne RA, Meisel DV et al. (2006) Exploration and habituation in intact

$4 \quad$ free moving Octopus vulgaris. Int J Comp Psychol 19: 426-438.

5 Long TM, Hanlon RT, Ter Maat A et al. (1989) Non-associative learning in the squid

6 Lolliguncula brevis (Mollusca, Cephalopoda). Mar Behav Physiol 16: 1-9. doi:

$7 \quad 10.1080 / 10236248909378736$

8 McCauley RD, Fewtrell J, Duncan AJ, et al. (2000) Marine seismic surveys - a study

9 of environmental implications. APPEA J 40: 692-708

10 Mooney TA, Nachtigall PE, Vlachos S (2009) Sonar-induced temporary hearing loss

11 in dolphins. Biol Lett 5: 565-567. doi: 10.1098/rsbl.2009.0099

12 Mooney TA, Hanlon RT, Christensen-Dalsgaard J, et al. (2010) Sound detection by

13 the longfin squid (Loligo pealeii) studied with auditory evoked potentials: sensitivity

14 to low-frequency particle motion and not pressure. J Exp Biol 213: 3748-3759. doi:

$15 \quad 10.1242 /$ jeb.048348

16 National Research Council (2005) Marine Mammal Populations and Ocean Noise:

17 Determining When Noise Causes Biologically Significant Effects. The National

18 Academies Press, Washington D.C.

19 Packard A, Karlsen HE, Sand O (1990) Low frequency hearing in cephalopods. J

20 Comp Physiol A 166: 501-505

21 Piniak WED, Mann, DA, Eckert SA et al. (2012) Amphibious hearing in sea turtles.

22 In: Popper AN, Hawkins A (eds) The Effects of Noise on Aquatic Life. $2^{\text {nd }}$

23 International Meeting on the Effects of Noise on Aquatic Life, Cork, August 2010.

24 Advances in experimental medicine and biology, vol. 730. Springer, pp. 83-87

25 Popper AN, Hastings MC (2009) The effects of anthropogenic sources of sound on 
1 fishes. J Fish Biol 75: 455-489. doi: 10.1111/j.1095-8649.2009.02319.x

2 Urick RJ (1983) Principles of underwater sound. McGraw-Hill

3 Wenz GM (1962) Acoustic ambient noise in the ocean: spectra and sources. J Acoust

$4 \quad$ Soc Am 34: 1936-1956. doi: 10.1121/1.1909155

5 Wilson M, Hanlon RT, Tyack PL et al. (2007) Intense ultrasonic clicks from

6 echolocating toothed whales do not elicit anti-predator responses or debilitate the

7 squid Loligo pealeii. Biol Lett 3: 225-227. doi: 10.1098/rsbl.2007.0005

8

$9 \quad$ Figure captions

10

11 Figure 1: Sound detection ranges for several cephalopod species, determined using

12 behavioral (B), conditioned (C), neurological $(\mathrm{N})$ or physiological (P) responses.

13 References from top to bottom: (1) Samson et al. (this conference, submitted), (2)

14 Komak et al. (2005), (3) Packard et al. (1990), (4) Mooney et al. (2010), (5) Hu et al.

15 (2009) twice, (6) Kaifu et al. (2008) (also indicated by numbers).

16

17 Figure 2: Hearing ranges of several marine organisms in comparison to two important

18 abiotic sound sources in the ocean. References: (2) Popper \& Hastings, 2009 (fish),

19 (3) Piniak et al., 2012 (sea turtles), (4) Au et al., 2000 (dolphins), (5) Wenz, 1962

20 (abiotic sound sources). References for the cephalopod hearing range are listed in

21 Figure 1.

22 


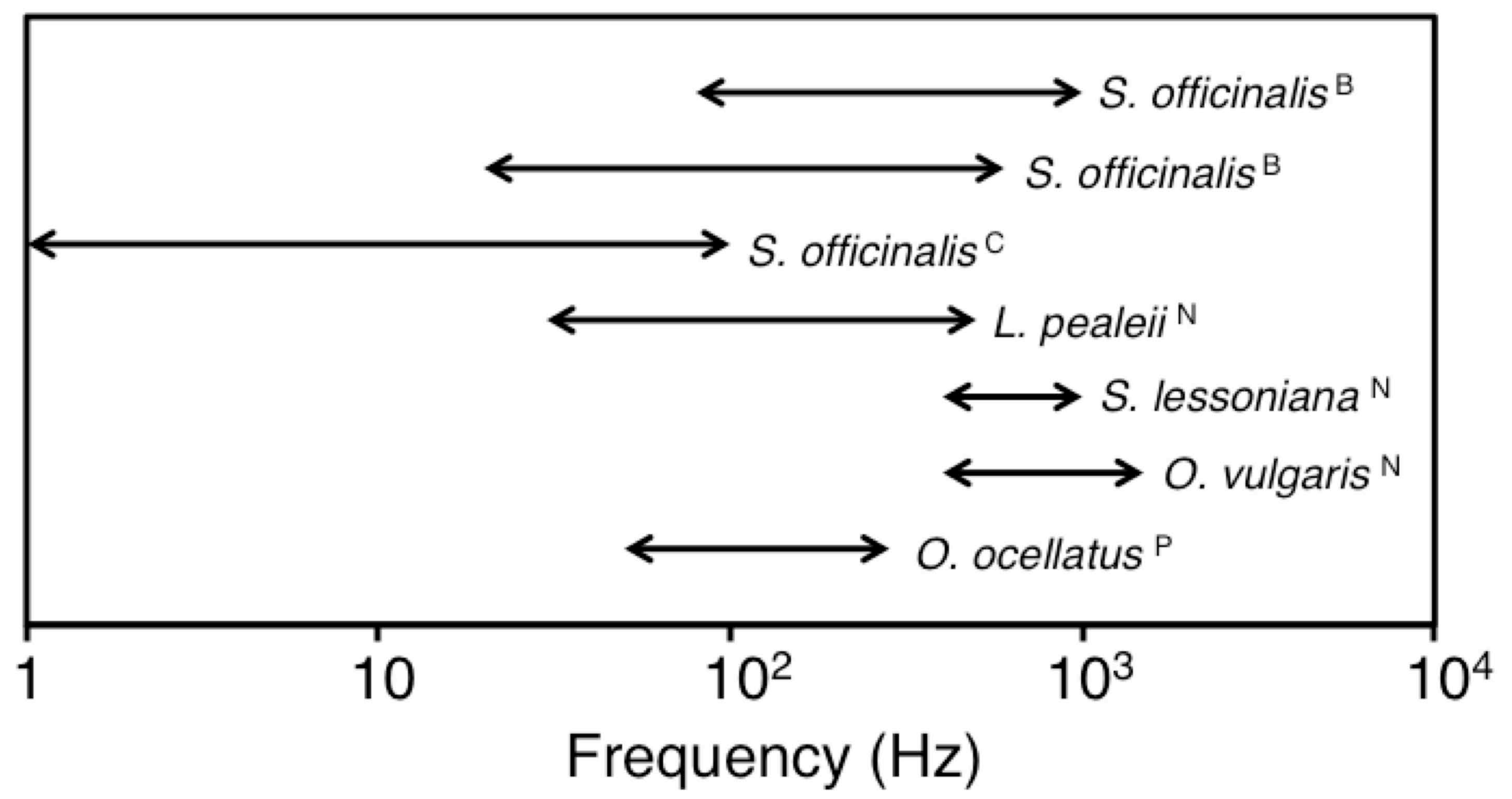




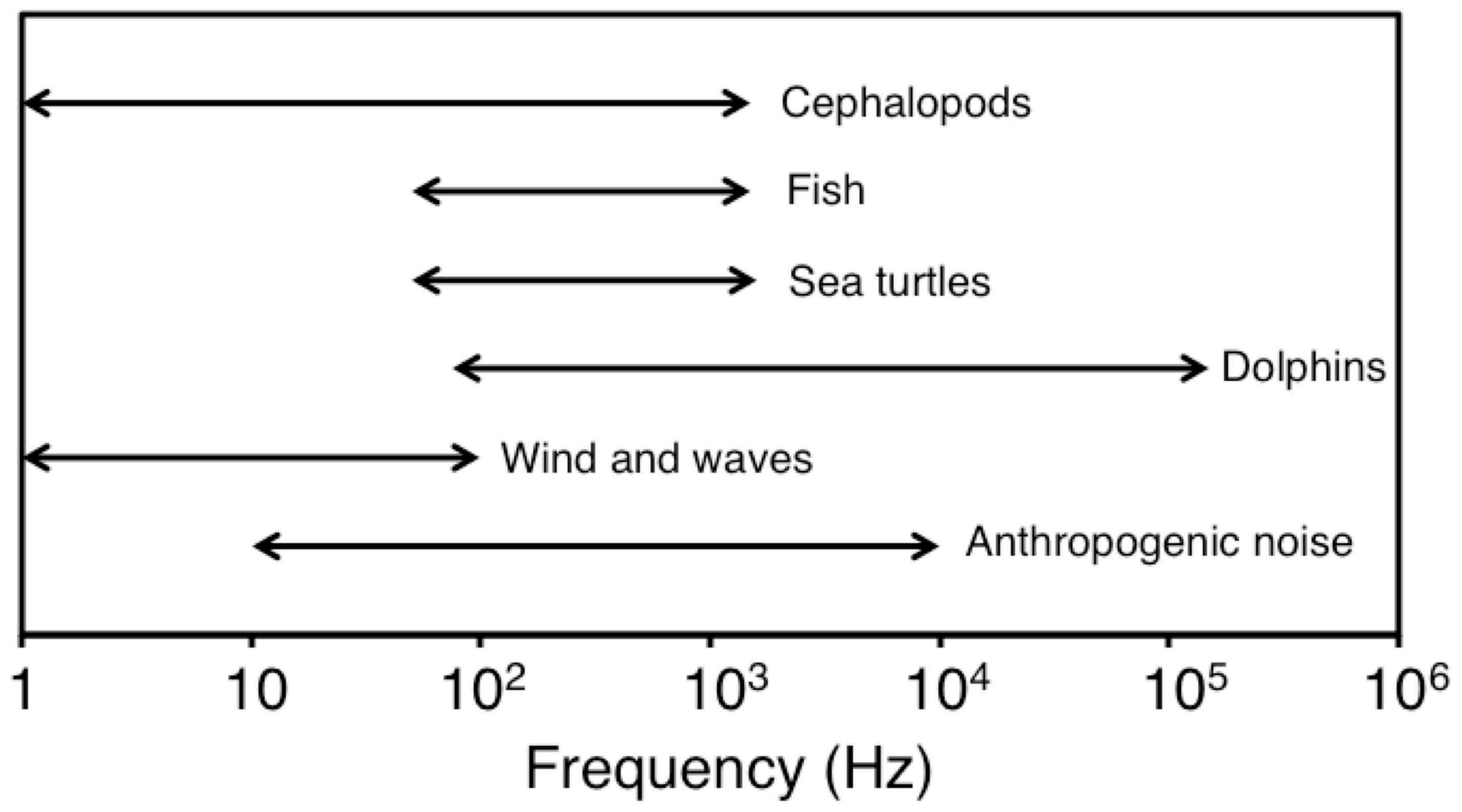

